Revista de la red interuniversitaria de estudios sobre las literaturas rioplatenses contemporáneas en Francia

$18 \mid 2018$

El río y la ciudad

\title{
Los laberintos de la sociedad
}

\section{Claudia Gilman}

\section{OpenEdition}

Journals

Edición electrónica

URL: http://journals.openedition.org/lirico/4637

DOI: $10.4000 /$ lirico.4637

ISSN: 2262-8339

Editor

Réseau interuniversitaire d'étude des littératures contemporaines du Río de la Plata

Referencia electrónica

Claudia Gilman, « Los laberintos de la sociedad », Cuadernos LIRICO [En línea], 18 | 2018, Puesto en línea el 22 septiembre 2018, consultado el 21 abril 2019. URL : http://journals.openedition.org/ lirico/4637 ; DOl : 10.4000/lirico.4637

Este documento fue generado automáticamente el 21 abril 2019.

\section{(c) $(1) \Theta \Theta$}

Cuadernos LIRICO está distribuido bajo una Licencia Creative Commons Atribución-NoComercialSinDerivar 4.0 Internacional. 


\section{Los laberintos de la sociedad}

\section{Claudia Gilman}

\section{REFERENCIA}

Rodríquez Pérsico, Adriana. Los unos y los otros. Comunidad y alteridad en la literatura latinoamericana. Villa María, Eduvim, 2017 
1 Como constata en su prólogo a este libro Adriana Rodríguez Pérsico, en una vida se escriben, finalmente, pocas cosas sobre pocos temas. Obsesiones, insistencias; son, en principio, escrituras que llegan al libro en una nueva figura. Diríase un legado. Esas obsesiones e insistencias reorganizan trabajos precedentes de una autora cuya presencia es importante en la vida académica actual, que se mueve en un territorio teórico crítico del que ya se ha apropiado y que le pertenece, como se verifica en la lectura. Diríase una firma.

Una de las hipótesis medulares que siguen sosteniendo los trabajos de Adriana Rodríguez Pérsico es que la literatura procesa todas las prácticas y todos los

\section{$>$}

Los unos y los otros. Comunidad y alteridac en la literatura latinoamericana

\section{Adriana}

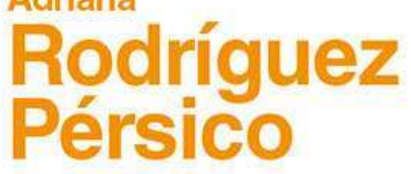
discursos -sociales, políticos, científicos, geográficos, demográficos, médicos, pedagógicos, religiosos, militares, económicos, infinitos etc. La literatura es una máquina que deglute, se alimenta y recicla todo tipo de materiales. La totalidad discursiva ingresa a la literatura abandonando cualquier alteridad intrínseca ya que todo cabe en la letra. Dicho de otro modo: propone que la literatura es un dispositivo todopoderoso y omnisciente que ficcionaliza al tiempo que se da a la tarea de objetivar.

El libro examina la elaboración e invención de discursos que desde fines de siglo XIX y buena parte del XX imaginan prácticas, ideas y palabras fraseando complejas instancias de inclusión y exclusión que van variando de espectro. Lo comunitario es flexible y puede tener la envergadura de un continente, una nación, un barrio, un arrabal. Se trata de palabras (locaciones) que bien podrían cubrir una serie geográfica entre la nada y lo inmenso. Interesa rastrear las diversas "nomenclaturas" que definen un nosotros, un yo o un otro cuyos meridianos y paralelos son lábiles: Río de la Plata, Argentina, Sudamérica, América Latina, Hispanoamérica, etc.

4 Los ideales, los enemigos, las políticas están presentes en la dialéctica comunidad/ alteridad por cuanto, siempre, al tiempo que se imaginan los relatos nacionales, continentales o regionales, se realiza en la escritura la autoinserción de quien escribe e interviene y según la inspiración que lo aliente. Las figuraciones autorales combinan las creadas con las que les son asignadas. Para dar un par de ejemplos: Juan Bautista Alberdi es el legislador, Sarmiento el educador y militar, José Martí el Apóstol, Rubén Darío, el "vate" como personalidad de culto, José Enrique Rodó, como el Próspero de La tempestad, un viejo maestro que guía a los jóvenes desde la oscuridad hasta la luz, fuente crucial para la corriente del antiimperialismo cultural que será retomada durante el proceso de la Reforma Universitaria.

5 En el análisis de la obra de Rubén Darío se señala un doble americanismo que reafirma las tradiciones al tiempo que corrobora la modernidad. En la imagen de la tierra prometida, el pasado enlaza con el futuro en un continuum temporal donde se unen las tradiciones locales con las extranjeras al presente de las máquinas y la industrialización. Sostiene 
Rodríguez Pérsico que en su "Canto a la Argentina" aparece otra patria de adopción que dibuja los contornos de una utopía. Atravesado por las derivas de la épica del poeta sensible, Darío reúne en Los raros una comunidad; un elenco de subjetividades heroicas, mártires, distintas. El poeta comparte esa sensibilidad y podría decirse que se identifica con Edgar Allan Poe, quien con sus alados pies de artista se opone al pragmatismo colectivo y es también una contrafigura del desconocido entre la multitud.

6 La autora traza un contrapunto entre Juan Bautista Alberdi y Domingo Faustino cuya ostensible oposición puede ser dialécticamente superada si se considera, como es el caso, que finalmente uno pensó la ley y el otro diseñó la educación de un país futuro. Ambos crearon lenguas que dieron como legado precioso al porvenir y coincidieron al concebir la escritura como militancia.

7 Rodríguez Pérsico rastrea el legado de Sarmiento al siglo venidero. Sus biografías de caudillos son la prueba de su desvelo por construir una identidad colectiva que opere como sustrato de la nación. En Conflicto y armonías de las razas en América-propone Rodríguez Pérsico- Sarmiento establece las bases para una retórica nacionalista que retomarán, tras la senda del maestro, Leopoldo Lugones, Manuel Gálvez y Ricardo Rojas, produciendo una literatura tanto ensayística como ficcional que ha servido para elaborar representaciones de la nacionalidad, construir linajes e identidades colectivas y forjar los mitos cuya cristalización acompaña los fastos del Centenario de la Revolución de mayo.

8 La literatura dibuja geografías y cuerpos, inscribe la topografía de la individualidad en una topografía comunitaria. La pregunta por la nacionalidad resulta una flexión de la pregunta por la distribución, la pertenencia y el derecho a ejercer el poder sobre determinados espacios

Rodríguez Pérsico enhebra sus argumentos en torno a nociones necesarias para fundar el análisis. Estas nociones centrales son raza, masa, patria y nación y tanto se las puede ver desde un crudo naturalismo pesimista como emergiendo triunfalmente en los discursos proféticos y utópicos.

10 El libro pasa revista a la huidiza e inclasificable geografía latinoamericana siguiendo el esquema desde la perspectiva que observa lo común y lo alterno en el marco de los procesos modernizadores. La autora propone considerar un canon literario y programático que explora obras de Carlos Bunge, Rubén Darío, Joaquín V. González, Leopoldo Lugones, José Martí, José Enrique Rodó, José Asunción Silva, Manuel Ugarte, entre otros.

11 Inspirado en la comunidad universal cantada por Walt Whitman, la palabra profética encarna en José Martí, para quien el poeta debe ocupar la máxima jerarquía en la sociedad ideal. Amenazado por la masa sorda, el pueblo, que se separa de ella cuando escucha al poeta, puede estrechar alianza y realizar el milagro de la totalidad. Esta comunidad es todavía mayor si se tiene en cuenta que en el debate sobre las razas Martí celebra la mezcla.

12 A fines del siglo XIX, el "antropólogo científico" Raimundo Nina había considerado de manera pesimista el futuro demográfico del Brasil, como sucedió en muchos discursos presuntamente científicos que promovían un ideal racial de pureza. Las hipótesis científicas del momento, avaladas por postulados eugenésicos, corroboraron los prejuicios raciales. Estas creencias y supuestos saberes se pueden ver en el análisis del relato de ciencia ficción de José Bento Monteiro Lobato 0 presidente negro ou $O$ Choque das raças. 
13 La problemática de la hegemónica y anglosajona América del Norte cala dolorosamente en Rodó, quien presenta la lucha entre espíritu y materia en términos que oponen América del norte y la América del Sur. Su Ariel traza una historia evolutiva de ideas y culturas que avanzan, teóricamente, hacia la plenitud, aunque como bien señala Adriana Rodríguez Pérsico: "El viejo maestro devela a sus discípulos los enigmas actuales al dar un salto adelante, que es, en rigor, hacia atrás puesto que halla el ideal en la restauración de culturas pasadas".

14 Manuel Ugarte acorta las especulaciones invitando directamente a observar el mapa de América para ver lo que "salta a los ojos", es decir, el contraste entre la unidad de los anglosajones y el "desmigajamiento" de los latinos en momentos en que estos son minorizados por una supuesta superioridad anglosajona demostrada, para el momento, científicamente a partir de supuestas señales históricas. Convencido de la fuerza de la unión letrada, para Ugarte los intelectuales son "agentes difusos" de los ideales bolivarianos; su antiimperialismo cuestiona por estrecho el concepto de nacionalidad. Más eminentemente político y volcado a los aspectos organizativos, es partidario de crear una confederación moral que se base en el acuerdo entre partidos dentro de cada nación y una estructura institucional.

En la base de los relatos de identidad colectiva hay siempre una pregunta esencialista rodeada de escrituras que proponen una deriva científica, en contacto con los saberes coetáneos. La teoría de la evolución brinda materiales a narrativas “darwinistas” en cuyas tramas están presentes temas como la selección nacional y la supervivencia de los más aptos. La emergencia de una "cultura científica" finisecular del siglo XIX la puede leer también en la nouvelle 0 alienista, de Joaquim Machado de Assis.

A partir de la época de las inmigraciones masivas el problema de las masas y la dificultad para dominarlas generó frenéticas especulaciones. En Buenos Aires, por lo menos, las masas que emergen de su sueño de criadero son ahora reales, temibles e ingobernables. En las multitudes se sepulta la singularidad del sujeto y se la reduce a la anomia del "hombre carbono", advierte el médico argentino José María Ramos Mejía mientras disecciona el cuerpo comunitario. La literatura "presiona las argumentaciones científicas desviando la prosa hacia los bordes de la ciencia y el comienzo de la ficción". En sus ensayos, que son ficciones sobre el poder, Ramos Mejía desarrolla una doctrina paranoica que encuentra siempre anomalía, enfermedad, locura. En su comunidad entran los valerosos gauchos, pero no el inmigrante, que es un otro total.

17 Recorre este libro una utopía crítica que es la "salida por el humor". Si bien no está planteado expresa ni estructuralmente en el volumen, la ironía y la burla siempre salvan. En casi todos los casos donde se llega a un punto muerto la única salida es el humor, la farsa y la deformación de los estereotipos. Lo establecido se desarma ante la risa.

En un caso esto se ve en Fray Mocho que, inscribiendo la picaresca en la biografía popular, hace visibles los restos que dejan los procesos de modernización. Mediante ese principio compositivo descompone "constelaciones adquiridas"; en este caso, la que igualaba crimen, ideología e inmigración. Del mismo modo, los sermones nacionalistas se disuelven en clave de farsa brasileña como se puede ver en el análisis de la novela Triste fim de Policarpo Quaresma (1911) de Alfonso Henriques de Lima Barreto. Lo mismo vale para el bricolage humorístico que propone Eduardo Holmberg en su novela Olimpio Pitango de Monalia a comienzos del siglo XX o la fusión de costumbrismo y humor en los textos de Arturo Cancela, Enrique Méndez Calzada y Enrique Loncán. Sus nombres se hacen más 
conocidos para el público dado que son colaboradores regulares de periódicos y revistas de grandes tiradas.

"La jocosidad y la burla se unen para producir un tipo de textualidad que toma distancia tanto del ademán pedagógico cuanto de la pose indignada", dirá la autora hablando de Loncán en particular; en esas palabras está la clave de la deriva teórica del texto. Dicho de otro modo: lo que se rubrica es la potencia corrosiva de la escritura. Buscando hacer una autopsia de la sociedad de su tiempo, Loncán interviene el género decimonónico de la causerie para cargarlo de contenido político. Su literatura derriba mitos y esencias, pero no repone nada sobre el vacío que deja, mostrando que no hay restitución o nada que restituir.

A su vez, el herético Cancela funda una estética interesada en procesar restos y desechos y practicar una lógica de la desubjetivación. Esa lógica se ríe de la cultura de conferencias que sazona la vida cultural porteña, en momentos en que se hacen frecuentes los viajes de eminencias internacionales de quienes se esperan pareceres sobre la moderna Buenos Aires para saciar y curar lo que Cancela llama "complejo de desierto". Antimimética y antimítica, la escritura de Cancela prolonga la tradición europea de la novela satírica, la novela de aventuras y el cuento filosófico de inspiración volteriano para refutar los mitos literarios de gauchos, indios, españoles o helenistas considerados como base para la identidad nacional.

21 Adriana Rodríguez Pérsico encara algunas batallas culturales en defensa de autores y textos olvidados o mal leídos como es el caso de estos autores humoristas. También realiza una vindicación de Elías Castelnuovo contra quienes han querido ver en su literatura solamente patetismo y mal gusto. Sin embargo, no se le reconoce la fundación de una estética de lo monstruoso como condición de la vida moderna, ni se ha reparado en que sus cuentos no velan una realidad segunda ni aspiran a una búsqueda moral. Los personajes que crea Castelnuovo están como vomitados por el capitalismo; son restos, ruinas, desechos.

Es imposible ejercer un gesto exhaustivo habida cuenta de la multiplicidad de autores y textos estudiados. Mencionamos, como al pasar, algunas hipótesis sobre la concepción de la escritura en Ricardo Piglia como actividad que restituye lo perdido; y el estudio, en Jorge Luis Borges, de un momento de su poética en momentos en que el autor está ya totalmente canonizado. Confirmando la confesión del propio Borges acerca del hecho de que sus segundas versiones son siempre inferiores a las primeras, este libro sugiere considerar una cierta pausa borgeana precisamente en el momento de su máxima celebridad mundial: el autor parece condenado a una perpetua reescritura cada vez más sensible a la entropía.

Al igual que como lo hace con Borges, en una hipótesis sugestiva y potente Adriana Rodríguez Pérsico propone una lectura, también en dos tiempos, de Oliverio Girondo. Los viajes concretos y reales de los primeros textos tan característicos, se trasforman, en Campo nuestro (1946), en viajes internos por mundos microscópicos. En esta elegía al campo Girondo deja la escenografía preferida de la modernidad. Con esta dejación de la ciudad y sus señales de progreso se conforma un imaginario nacionalista reticente a cualquier tentativa cosmopolita.

Una marca de estilo y método reconocible en Adriana Rodríguez Pérsico es el minucioso análisis textual, constante, imperativo y probatorio siempre. 
Dicho sea de paso, ya que es imposible ser exhaustiva con el amplio corpus de textos y autores que se trabajan en el libro, Adriana Rodríguez Pérsico hace un gesto inclusivo al incorporar al corpus autores brasileños como Sílvio Romero, Paulo Prado, Lima Barreto, Euclides da Cunha, Machado de Assis.

26 El libro ha sido editado por Eduvim, de la Universidad de Villa María, en la colección Zona de críticas, dedicada a la crítica literaria y también a recopilaciones de textos que, como en este caso, recomponen en otra estructura series de textos que en sus publicaciones originales no dialogaban entre sí.

\section{AUTORES}

\section{CLAUDIA GILMAN}

CONICET/Universidad de Buenos Aires

claudiagilman@gmail.com 